\title{
Potential action of extract of Acmella oleracea (L.) R.K. Jansen to control Amblyomma cajennense (Fabricius, 1787) (Acari: Ixodidae) ticks
}

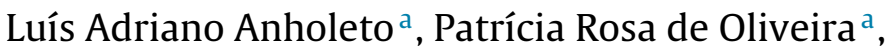 \\ Rodney Alexandre Ferreira Rodrigues ${ }^{\mathrm{b}}$, Caroline dos Santos Spindola ${ }^{\mathrm{b}}$, \\ Marcelo Bahia Labruna ${ }^{\mathrm{c}}$, Marcos Aparecido Pizano ${ }^{\mathrm{d}}$, Karina Neoob de Carvaldo Castro ${ }^{\mathrm{e}}$, \\ Maria Izabel Camargo-Mathias ${ }^{\mathrm{a}, *}$

\footnotetext{
a Department of Biology, Institute of Biosciences, São Paulo State University, UNESP, Av. 24 A, no 1515, 199, 13506-900, Rio Claro, SP, Brazil

${ }^{b}$ Division of Chemistry of Natural Products, CPQBA/UNICAMP, Av. Alexandre Cazellato, 999, 13140-000, Paulínia, SP, Brazil

${ }^{\mathrm{c}}$ Department of Preventive Veterinary Medicine and Animal Health, University of São Paulo- USP, Av. Prof. Dr. Orlando Marques de Paiva, 87, 05508-270, Cidade Universitária, São Paulo, SP, Brazil

${ }^{\mathrm{d}}$ Department of Ecology, Institute of Biosciences, São Paulo State University, UNESP, Av. 24 A, 1515, 13506-900, Rio Claro, SP, Brazil

e Embrapa Meio-Norte, BR 343, km 35, CP 341, 64.200-970, Parnaíba, PI, Brazil
}

\section{A R T I C L E I N F O}

\section{Article history:}

Received 17 May 2016

Received in revised form 23 August 2016

Accepted 29 September 2016

Available online 30 September 2016

\section{Keywords:}

Natural control

Ticks

Acaricide

Jambu

$\mathrm{LC}_{50}$

\begin{abstract}
A B S T R A C T
The use of synthetic acaricides is currently the main method to control ticks. However, the indiscriminate use of these chemicals can lead to the selection of resistant individuals and in the accumulation of chemical residues in the environment, contaminating the soil and water streams, consequently affecting the flora, fauna, and the human beings as well. In this sense, the objective of this study was to investigate the acaricidal effect of crude ethanolic extract of Acmella oleracea (L.) R.K. Jansen aerials parts at different concentrations on fed males and semi-engorged females of $A$. cajennense s.s. An in vitro bioassay (Adult Immersion Test) was carried out to determine the lethal concentration $50\left(\mathrm{LC}_{50}\right)$ of ethanolic extract, calculated by Probit analysis. The results showed that the fed males were sensitive to all the concentrations of A. oleracea ethanolic extract, and mortality rate progressively increased (15-65\%) in higher ethanolic extract concentrations. However, semi-engorged females were not sensitive to all the concentrations used here. In the highest concentration $(100 \mathrm{mg} / \mathrm{mL})$, a mortality rate of $100 \%$ was observed after $72 \mathrm{~h}$ of exposure, indicating that the acaricidal effect would probably be dose-dependent. The $\mathrm{LC}_{50}$ values obtained for the fed $A$. cajennense s.s males and semi-engorged females were $29.4534 \mathrm{mg} / \mathrm{mL}$ (limits: $24.4467-41.3847 \mathrm{mg} / \mathrm{mL}$ ) and $\mathrm{LC}_{50}=17.6335 \mathrm{mg} / \mathrm{mL}$ (limits: $5.2506-23.5335 \mathrm{mg} / \mathrm{mL}$ ), respectively.
\end{abstract}

(c) 2016 Elsevier GmbH. All rights reserved.

\section{Introduction}

Amblyomma cajennense (Fabricius, 1787) ticks are ectoparasites of great medical and veterinary importance, once they parasitize domestic ungulates and are associated with the transmission of several pathogens to other animals and human beings as well (Beati et al., 2013; Estrada-Peña et al., 2014).

The adult tick $A$. cajennense s.l., popularly known as the star tick or horse tick, is the main vector of the bacterium Rickettsia rickettsii, etiologic agent of Brazilian spotted fever (Rocky Mountains fever or tick fever), whose infection can lead the host to death (Soares et al., 2015). In addition, these ticks are vectors of Theileria equi,

\footnotetext{
* Corresponding author.

E-mail address: micm@rc.unesp.br (M.I. Camargo-Mathias).
}

etiological agent of equine piroplasmosis (Scoles and Ueti, 2013; Scoles et al., 2011).

Several studies have focused on these ectoparasites, not only due to their medical and veterinary importance, but also aiming to find new and efficient strategies to control them without harming the environment or non-target organisms (Oliveira et al., 2009, 2008; Roma et al., 2009).

Although several methods for the effective control of ticks have been tried, the most effective is still the use of synthetic chemical acaricides. However, this method causes serious damages to the environment and public health; in addition, the chemicals are costly and the technique requires specialized labor and appropriate equipment (Nolan, 1985; Pruett, 1999). Furthermore, the chemical residues accumulate in the environment, contaminating the soil, water streams, and, consequently, the fauna, flora and the human beings as well (Nolan, 1985; Oliveira et al., 2009, 2008; Pruett, 1999; Roma et al., 2009). 
Acaricides with different chemical formulations and active ingredients have been used in an attempt to overcome the survival strategies of the ticks, which involve reduced penetration or uptake of the chemical, metabolic changes and storage/excretion of the substance used (Abbas et al., 2014; Nolan, 1985). The indiscriminate use of different synthetic chemicals has been responsible for the emergence of resistant tick strains (Abbas et al., 2014; Crampton et al., 1999).

Therefore, control strategies based on the use of acaricides produced from plant extracts are very promising alternatives, especially considering the large amounts and the toxic effects of synthetic acaricides used today, affecting the environment and nontarget organisms as well (Borges et al., 2011; Dietrich et al., 2006; Matos et al., 2014a; Panella et al., 2005; Remedio et al., 2015; Vendramini et al., 2012).

Acmella oleracea is a plant introduced from Brazil and is found in the tropical regions close to the Equator, Africa, Asia and South America (Favoreto and Gilbert, 2010). In Brazil, it is popularly known as Jambu, watercress-of-Pará, watercress-of-the-north or watercress-bravo, being a typical vegetable in the north region, much used in local cuisine (Favoreto and Gilbert, 2010). It is an annual, perennial herbaceous plant, up to $40 \mathrm{~cm}$ of height, almost creeping, which presents small yellowish flowers arranged in globular terminal sections of approximately $1 \mathrm{~cm}$ (Favoreto and Gilbert, 2010). The ingestion of their aerial parts (flowers, leaves and stem) causes tongue tingling, a result of the anesthetic effect of secondary metabolites present in the plant (Dubey et al., 2013; Favoreto and Gilbert, 20100; Ramsewak, 1999). It is also used in popular medicine as potent analgesic and local anesthetic in the treatment of mouth ulcers, herpes, throat infections; in addition to presenting insecticide, fungicide, and fungistatic activities (Fabry et al., 1996; Nigrinis et al., 1986; Ramsewak, 1999; Torres and Chávez, 2001).

Studies conducted by Castro et al. (2014) demonstrated the acaricidal effects of the extract produced from the aerial parts (flower, leaf and stem) of this plant. These extracts have been used to control Rhipicephalus microplus ticks, presenting great efficacy in the control of larvae and engorged females of this species (Castro et al., 2014).

The main biological effects reported herein have been assigned to spilanthol or affinin [N-2-Metilpropil-2,6,8-decatrienamida or $\mathrm{N}$-isobutyl-2E,6Z,8E-decatrienamida], an aliphatic alcamid of molecular formula $\mathrm{C}_{14} \mathrm{H}_{23} \mathrm{NO}$, abundantly found in the $A$. oleracea flowers, leaves and stem (Ramsewak, 1999).

Therefore, the present study evaluated the acaricidal potential of A. oleracea (L.) R.K. Jansen ethanolic extract, obtained from the aerial parts (flower, leaf and stem) of the plant, to control fed males and semi-engorged females of $A$. cajennense s.s. (Fabricius, 1787) adults ticks. For this purpose, the Adult Immersion Test (Drummond et al., 1973 ) was used to estimate the $50 \%$ lethal concentration $\left(\mathrm{LC}_{50}\right)$ of extract for this species.

\section{Materials and methods}

\subsection{Preparing the crude Acmella oleracea (L.) R.K. Jansen ethanol extract}

The extract of A. oleracea was provided by PhD Rodney A. F. Rodrigues from the Chemical, Biological and Agricultural Pluridisciplinary Research Center CPQBA/UNICAMP, Campinas, SP, Brazil. The plants were cultivated in the experimental field (geographic coordinates, $22^{\circ} 47^{\prime} 52^{\prime \prime}$ S, $47^{\circ} 6^{\prime} 49^{\prime \prime} \mathrm{W}$ ) of CPQBA, Paulinia, SP, Brazil, and identified by PhD John F. Pruski from the Missouri Botanical Garden (USA). The voucher specimen was 181.452, deposited at the CPQBA Herbarium (number 181,452). Authorization Genetic Heritage access (Cgen) number 010577/2014-9.
The aerial parts (flowers, leaves and stem) of A. oleracea were dried and milled. The extraction was then performed under mechanical agitation with $96^{\circ}$ GL ethanol (1:5 ratios, plant: solvent, $\mathrm{w} / \mathrm{v}$ ) in a stainless steel vessel for $1.5 \mathrm{~h}$. The remaining residue was filtered and the extraction step was repeated twice. The final product was filtered, pooled, concentrated under vacuum and then freeze dried to determine the process yield.

\subsection{Analytical monitoring of spilanthol}

The quantification of spilanthol in the extract was performed through gas chromatography, using a gas chromatograph coupled with a mass detector (GC-MS, Agilent ${ }^{\circledR} 5890$ Series II mass selective detector Agilent ${ }^{\circledR} 5970$ EI $70 \mathrm{eV}$ ) equipped with a fused silica column WCOT, HP5-MS, Agilent ${ }^{\circledR}$, dimensions $30 \mathrm{~m} \times 0.25 \mathrm{~mm} \times 0.25 \mu \mathrm{m}$. The analysis conditions were: injector temperature: $220^{\circ} \mathrm{C}$; detector temperature: $250^{\circ} \mathrm{C}$, temperature program: $60-240^{\circ} \mathrm{C}\left(3^{\circ} \mathrm{C} / \mathrm{min}\right)$, sample injection using split mode at $1: 40$ ratio, Helium gas was used as the carrier $0.7 \mathrm{bar}, 1 \mathrm{~mL} / \mathrm{min}$. The spilanthol percentage was determined by GC/MS analysis comparing mass fragmentation pattern and the database library from the National Institute of Standards and Technology (NIST) Mass Spectral Search Program ${ }^{\circledR}$ (2005), with $32.4 \%$ of purity from normalization method.

\subsection{Maintenance of Amblyomma cajennense (Fabricius, 1787) ticks}

Amblyomma cajennense s.s. ticks were provided by PhD Marcelo Bahia Labruna from the Department of Preventive Veterinary Medicine and Animal Health, University of Sao Paulo (USP), SP, Brazil. The ticks were maintained under controlled conditions $\left(28 \pm 1^{\circ} \mathrm{C}, 85 \%\right.$ humidity and $12 \mathrm{~h}$ photoperiod) in BOD (Biological Oxygen Demand) incubator at the Biology Department - UNESP, campus Rio Claro, SP, Brazil.

The adult fed males and semi-engorged females were obtained by artificial infestations on Botucatu Genetic Group rabbit hosts at the Animal Facility from UNESP, Rio Claro Campus, SP, Brazil, following Bechara et al. (1995) protocol. The rabbits, weighing 3-3.5 kg, were obtained from the Animal Facility of UNESP, campus Botucatu, SP, Brazil and housed in the Animal Facility of UNESP, Rio Claro Campus, SP, Brazil. Animals did not have prior contact with ticks or acaricides and were kept under controlled conditions. During the entire experiment, animals were maintained in cages and received water and rabbit food ad libitum. This study was approved by the Ethics Committee for Animal Experimentation of UNESP, Rio Claro Campus, SP, Brazil, protocol number 11/2015.

The semi-engorgement feeding stage was chosen to approximate the experiment to field conditions, once in this phase the ticks remain attached to the host ingesting blood, causing damages to the host organism and transmitting pathogens.

\subsection{Adult immersion test (AIT)}

\subsubsection{Bioassay 1 - mortality interval protocol}

The Adult Immersion Test (AIT) described by Drummond et al. (1973) was used to determine the mortality interval $A$. cajennense s.s. fed males and semi-engorged females.

Fed $A$. cajennense s.s. males weighing $10 \mathrm{mg}$ on average (about ten days feeding on rabbit hosts) and semi-engorged females adults (about ten days of feeding on rabbit hosts) weighing $27 \mathrm{mg}$ on average ( 280 couples) were collected from artificial infestation on five rabbit hosts ( 56 couples on each rabbit). Prior to the experiment, the ticks were washed in running tap water and dried with soft absorbent paper. Then, the individuals were divided into seven groups of homogeneous weights $(p>0.05), 10$ ticks for each 


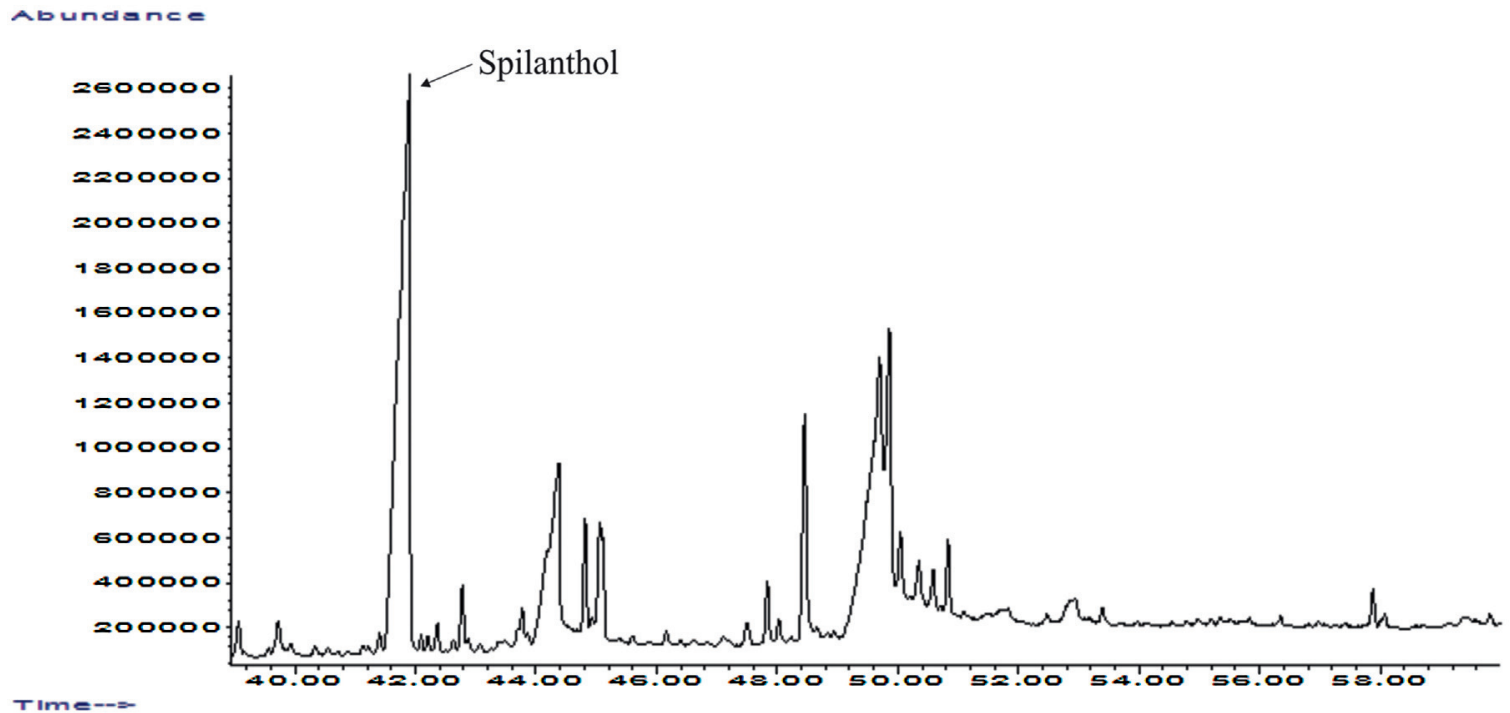

Fig. 1. GC/MS analysis chromatogram of A. oleracea crude extract; spilanthol was detected at $41.9 \mathrm{~min}$.

group. The groups were treated as follows: Control group 1-Ticks immersed in distilled water; Control group 2-ticks immersed in $50 \%$ ethanol and 1\% DMSO; Treatments 1 to 5 -ticks immersed in the concentrations of $6.2 ; 12.5 ; 25 ; 50$ and $100 \mathrm{mg} / \mathrm{mL}$ of $A$. oleracea ethanolic extract, respectively, obtained by the dilution into $50 \%$ ethanol and $1 \%$ DMSO. The initial concentrations of the extract were established according to Castro et al. (2014). The tests were performed in duplicate.

The ticks were immersed in the concentrations for $5 \mathrm{~min}$, dried in absorbent paper, mounted on labeled Petri dishes, and kept in BOD incubator $\left(28 \pm 1{ }^{\circ} \mathrm{C}, 85 \%\right.$ humidity and $12 \mathrm{~h}$ photoperiod). To determine the mortality potential of the A. oleracea ethanol extract on males and semi-engorged females, daily observations were made for 7 days. This period was suggested by Oliveira et al. (2008) in studies with $R$. sanguineus s.l. females subjected to fipronil, since the acaricide reaction is not immediate, acting slowly on the physiology of the individuals and the morphological alterations usually occur after this period.

In this bioassay, the ticks were exposed to carbon dioxide for $30 \mathrm{~min}$ and gently touched with the tip of a paintbrush to stimulate movement. Individuals not moving at all after $10 \mathrm{~min}$ were considered dead; and alterations such as a progressive decrease in locomotor capacity, prostration in inverted position, stretching of all legs, paralysis, and morphological alterations (e.g. integument consistency and color) were also observed.

\subsubsection{Bioassay 2 - determining the lethal concentration $50 \%$}

After determining the mortality interval $(12.5-50 \mathrm{mg} / \mathrm{mL})$ in bioassay 1 , new dilutions were performed to obtain concentrations within this mortality interval.

Fed males weighing $10 \mathrm{mg}$ on average and semi-engorged females adults (about ten days of feeding on rabbit hosts) weighing $27 \mathrm{mg}$ on average ( 320 couples) were collected from artificial infestation on five rabbits' hosts (64 couples of ticks each rabbit). Prior to the experiment, ticks were washed in running tap water and dried with soft absorbent paper. The individuals were then divided into eight groups with homogenous weights $(p>0.05), 10$ ticks each group. The groups were treated as follows: Control Group 1-ticks immersed in distilled water; Control Group 2-ticks immersed in $50 \%$ ethanol and $1 \%$ DMSO; Treatments 1 to 6 -ticks immersed in the concentrations of $14.3 ; 16.6 ; 20 ; 25 ; 33$ and $40 \mathrm{mg} / \mathrm{mL}$ of A. oleracea ethanolic extract, respectively, obtained by the dilution into $50 \%$ ethanol and 1\% DMSO. The ticks were immersed in the concen- trations for $5 \mathrm{~min}$, dried in absorbent paper, mounted on labeled Petri dishes, and kept in BOD incubator $\left(28 \pm 1{ }^{\circ} \mathrm{C}, 85 \%\right.$ humidity and $12 \mathrm{~h}$ photoperiod). To determine the mortality potential of the A. oleracea ethanol extract on males and semi-engorged females, daily observations were made for 7 days. This period was suggested by Oliveira et al. (2008) in studies with $R$. sanguineus s.l. females subjected to fipronil, since the action of the acaricide is not immediate, acting slowly on the physiology of the individuals and the morphological alterations usually occur after this period.

As in bioassay 1 , the ticks were exposed to carbon dioxide for $30 \mathrm{~min}$ and gently touched with the tip of a paintbrush to stimulate movement. Individuals not moving at all after 10 min were considered dead; and alterations such as decrease in locomotor capacity, prostration in inverted position, stretching of all legs, paralysis, and morphological alterations (e.g. integument consistency and color) were also observed.

\subsection{Statistical analysis}

The mortality interval obtained for the fed A. cajennense s.s. males and semi-engorged females in Bioassay 1 and the mortality data obtained in Bioassay 2 were analyzed through one-way analysis of variance (ANOVA) with the application of post hoc test of Tukey, significance levels set at $\mathrm{p}<0.05$, using the software GraphPad Prism v.6 (GraphPad Software Inc., San Diego, CA, EUA). The mortality data obtained in Bioassay 2 were subjected to Probit analysis using the software BioStat v5 (AnalystSoft, 2015) to calculate the lethal concentration 50\% ( $\mathrm{LC}_{50}$ ) and 95\% confidence interval.

\section{Results}

\subsection{Crude A. oleracea (L.) R.K. Jansen ethanolic extract}

Crude ethanolic extract had the yield of $7.7 \pm 0.08 \%$ on a dry basis. Analytical monitoring of the presence of spilanthol in the extract was performed by gas chromatography (Fig. 1). The ion fragments of spilanthol were consistent to the ion fragments detected in the NIST database, presenting $90 \%$ match as well as a confirmatory compound structure. The total ion chromatogram of the crude extract of $A$. oleracea also showed the presence of spilanthol, where the chromatographic peak was produced at retention time of 41.9 min (Fig. 1 ). 


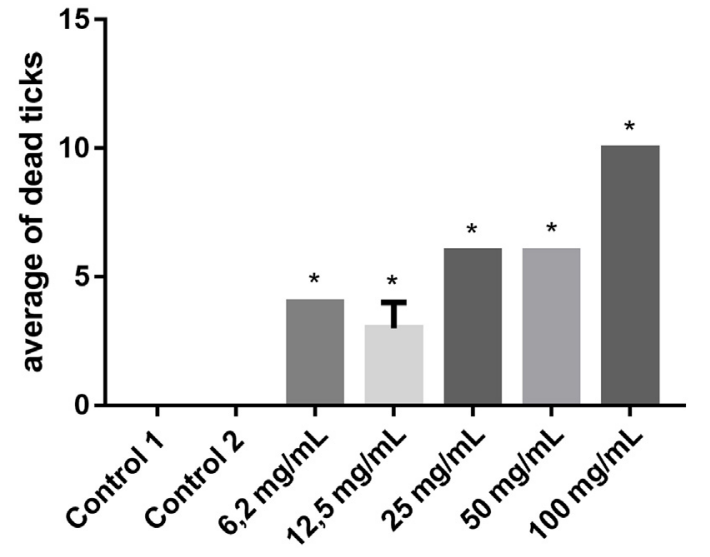

Fig. 2. Bioassay 1: average of dead Amblyomma cajennense s.s. male ticks on the 7th day of exposure to different Acmella oleracea ethanolic extract concentrations. *indicates statistically significant difference $(\mathrm{p}<0.05)$. Control $1=$ distilled water; Control $2=50 \%$ ethanol and $1 \%$ DMSO.

\subsection{A. oleracea ethanolic extract efficacy against A. cajennense males}

A. oleracea ethanolic extract efficacy against $A$. cajennense s.s. fed males was obtained using 10 different concentrations of extract, tested in duplicate (Tables $1,3,5$ ).

Bioassay 1 revealed that the male ticks were sensitive to all the ethanolic extract concentrations used here (Fig. 2). At the lowest concentration $(6.2 \mathrm{mg} / \mathrm{mL})$, dead ticks were found as from the 6 th day (Table 1). However, after the treatment with the concentrations 25,50 and $100 \mathrm{mg} / \mathrm{mL}$, dead ticks were observed on the 1 st day (Table 1). At these concentrations, the individuals displayed a progressive decrease in the locomotor activity, prostration in inverted position, stretching of all legs and paralysis. The mortality rate (50-100\%) increased with higher concentrations of the ethanolic extract $(25,50$ and $100 \mathrm{mg} / \mathrm{mL}$ ) (Fig. 2; Table 1). In higher concentrations, the ethanolic extract effects increased throughout the observations period. The 6th and 7th days of treatment showed the highest mortality rates (Table 1 ), the highest concentration of ethanolic extract $(100 \mathrm{mg} / \mathrm{mL})$ showed a mortality of $60 \%$ on the 1 st day and $100 \%$ on the 2 nd day of the experiment (Table 1 ).

In the individuals belonging to control groups 1 and 2, mortality was not statistically significant and no behavioral changes or any abnormality regarding the morphology, coloration and consistence of the integument were visually observed during the 7-day observation period (Fig. 2; Table 1).

The results of Bioassay 1 showed that the mortality interval of fed A. cajennense s.s. males was between 12.5 and $50 \mathrm{mg} / \mathrm{mL}$ of the A. oleracea ethanolic extract. Based on these data, new dilutions were performed and new concentrations were obtained and used in Bioassay 2.

The results obtained in Bioassay 2 indicate that males were sensitive to all the ethanolic extract concentrations of the (Fig. 3; Table 3 ). In this bioassay, tick mortality progressively increased $(15-65 \%)$ in higher concentrations of the ethanolic extract (14.3; $16.6 ; 20 ; 25 ; 33$; and $40 \mathrm{mg} / \mathrm{mL}$ ) (Fig. 3; Table 3). The highest mortality rate was observed from the 4 th to 7 th day of treatment (Table 3).

In the groups comprising fed males treated with the A. oleracea ethanolic extract concentrations used in Bioassay 2, the individuals displayed immediate reactions, such as the decrease in the locomotor activity, prostration in inverted position, stretching of all legs, paralysis (as observed in Bioassay 1) and some external morphological alterations (dehydrated integument), demonstrating that these individuals can progressively lose vitality, and eventually die.

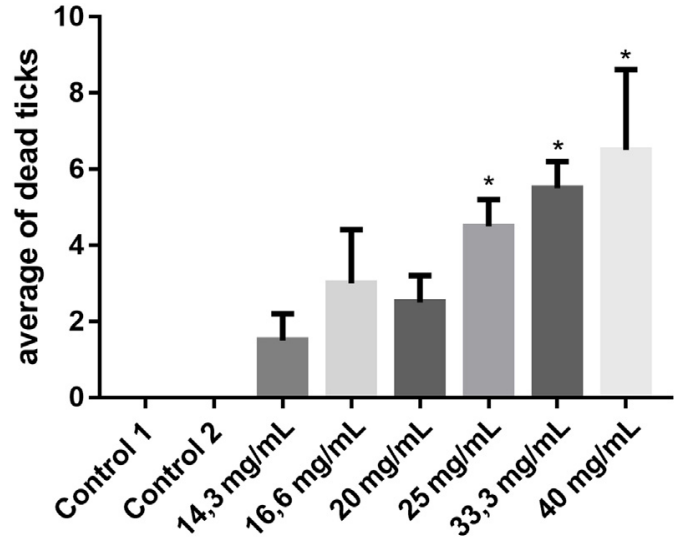

Fig. 3. Bioassay 2: average of dead Amblyomma cajennense s.s. male ticks on the 7th day of exposure to different Acmella oleracea ethanolic extract concentrations. ${ }^{*}$ indicates statistically significant difference $(p<0.05) 1$. Control $1=$ distilled water; Control $2=50 \%$ ethanol and $1 \%$ DMSO .

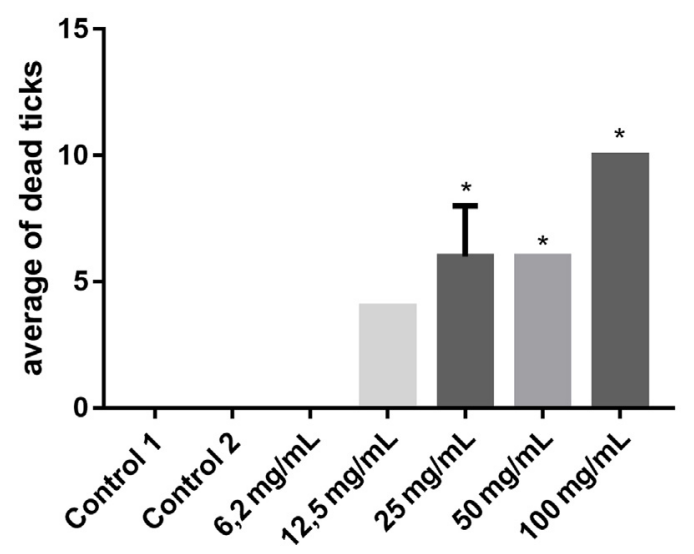

Fig. 4. Bioassay 1: average of dead semi-engorged Amblyomma cajennense s.s female ticks on the 7th day of exposure to different concentrations of Acmella oleracea ethanolic extract. * indicates statistically significant difference $(p<0.05)$ 1. Control $1=$ distilled water; Control $2=50 \%$ ethanol and $1 \%$ DMSO.

In the individuals belonging to control groups 1 and 2, mortality was not statistically significant and the individuals did not display any behavioral changes or abnormality regarding the morphology and consistence of the integument during the 7-day observation period (Fig. 3; Table 3).

The mortality data obtained in Bioassay 2 were submitted to Probit analysis to estimate the lethal concentration 50\% $\left(\mathrm{LC}_{50}\right)$ and the $95 \%$ confidence interval, $\mathrm{g}(95)$ : $\mathrm{LC}_{50}=29.4534 \mathrm{mg} / \mathrm{mL}$ (limits: 24.4467-41.3847 mg/mL) (Table 5).

\subsection{A. oleracea ethanolic extract efficacy against A. cajennense semi-engorged females}

The efficacy $A$. oleracea ethanolic extract against $A$. cajennense s.s. semi-engorged females was obtained using 10 different concentrations of the extract, tested in duplicate (Tables 2, 4, 6).

Bioassay 1 revealed that $A$. cajennense s.s. semi-engorged females were not sensitive to all the ethanolic extract concentrations used here (Fig. 4). In the lowest concentration $(6.2 \mathrm{mg} / \mathrm{mL})$, dead ticks were not found during the 7-day observation period (Table 2). In the concentration of $12.5 \mathrm{mg} / \mathrm{mL}$, dead ticks were observed from the 2 nd to 7 th day (Table 2 ). However, after the treatment with the concentrations 25,50 and $100 \mathrm{mg} / \mathrm{mL}$, dead ticks were found from the 1 st to 7 th day (Table 2). At these concentrations, the individuals displayed a progressive decrease in the 
Table 1

Bioassay 1: percentage of dead Amblyomma cajennense s.s. male ticks exposed to different concentrations of Acmella oleracea ethanolic extract.

\begin{tabular}{|c|c|c|c|c|c|c|c|}
\hline \multirow[t]{2}{*}{ Concentration of extract $(\mathrm{mg} / \mathrm{mL})$} & \multicolumn{7}{|c|}{ Percentage of dead ticks/days of treatment (\%) } \\
\hline & 1 st day & 2 nd day & 3 rd day & 4 th day & 5 th day & 6 th day & 7 th day \\
\hline Control 1 (distilled $\mathrm{H}_{2} 0$ ) & 0 & 0 & 0 & 0 & 0 & 0 & 0 \\
\hline Control 2 ( $50 \%$ ethanol $1 \%$ DMSO) & 0 & 0 & 0 & 0 & 0 & 0 & 0 \\
\hline 6.2 & 0 & 0 & 0 & 0 & 0 & $10 \%$ & $15 \%$ \\
\hline 12.5 & 0 & $10 \%$ & $10 \%$ & $10 \%$ & $10 \%$ & $15 \%$ & $15 \%$ \\
\hline 25 & $10 \%$ & $20 \%$ & $40 \%$ & $40 \%$ & $40 \%$ & $50 \%$ & $50 \%$ \\
\hline 50 & $20 \%$ & $20 \%$ & $60 \%$ & $60 \%$ & $60 \%$ & $60 \%$ & $70 \%$ \\
\hline 100 & $60 \%$ & $100 \%$ & $100 \%$ & $100 \%$ & $100 \%$ & $100 \%$ & $100 \%$ \\
\hline
\end{tabular}

Table 2

Bioassay 1: percentage of dead semi-engorged Amblyomma cajennense s.s. female ticks exposed to different concentrations of Acmella oleracea ethanolic extract. .

\begin{tabular}{|c|c|c|c|c|c|c|c|}
\hline \multirow[t]{2}{*}{ Concentration of extract $(\mathrm{mg} / \mathrm{mL})$} & \multicolumn{7}{|c|}{ Percentage of dead ticks/days of treatment (\%) } \\
\hline & 1 st day & 2 nd day & 3 rd day & 4 th day & 5 th day & 6 th day & 7 th day \\
\hline Control 1 (distilled $\mathrm{H}_{2} 0$ ) & 0 & 0 & 0 & 0 & 0 & 0 & 0 \\
\hline Control 2 (50\% ethanol 1\% DMSO) & 0 & 0 & 0 & 0 & 0 & 0 & 0 \\
\hline 6.2 & 0 & 0 & 0 & 0 & 0 & 0 & 0 \\
\hline 12.5 & 0 & $20 \%$ & $20 \%$ & $20 \%$ & $30 \%$ & $40 \%$ & $40 \%$ \\
\hline 25 & $10 \%$ & $20 \%$ & $30 \%$ & $40 \%$ & $50 \%$ & $50 \%$ & $60 \%$ \\
\hline 50 & $20 \%$ & $50 \%$ & $50 \%$ & $60 \%$ & $60 \%$ & $60 \%$ & $80 \%$ \\
\hline 100 & $60 \%$ & $80 \%$ & $100 \%$ & $100 \%$ & $100 \%$ & $100 \%$ & $100 \%$ \\
\hline
\end{tabular}

Table 3

Bioassay 2: percentage of dead Amblyomma cajennense s.s. male ticks exposed to different concentrations of Acmella oleracea ethanolic extract.

\begin{tabular}{|c|c|c|c|c|c|c|c|}
\hline \multirow[t]{2}{*}{ Concentration of extract $(\mathrm{mg} / \mathrm{mL})$} & \multicolumn{7}{|c|}{ Percentage of dead ticks/days of treatment (\%) } \\
\hline & 1 st day & 2 nd day & 3 rd day & 4 th day & 5 th day & 6 th day & 7 th day \\
\hline Control 1 (distilled $\mathrm{H}_{2} 0$ ) & 0 & 0 & 0 & 0 & 0 & 0 & 0 \\
\hline Control 2 (50\% ethanol 1\% DMSO) & 0 & 0 & 0 & 0 & 0 & 0 & 0 \\
\hline 14.3 & 0 & 0 & $5 \%$ & $15 \%$ & $15 \%$ & $15 \%$ & $15 \%$ \\
\hline 16.6 & 0 & $5 \%$ & $20 \%$ & $30 \%$ & $30 \%$ & $30 \%$ & $30 \%$ \\
\hline 20 & $10 \%$ & $10 \%$ & $15 \%$ & $25 \%$ & $25 \%$ & $25 \%$ & $25 \%$ \\
\hline 25 & $10 \%$ & $15 \%$ & $20 \%$ & $40 \%$ & $40 \%$ & $40 \%$ & $45 \%$ \\
\hline 33 & $5 \%$ & $20 \%$ & $35 \%$ & $45 \%$ & $45 \%$ & $45 \%$ & $55 \%$ \\
\hline 40 & $15 \%$ & $30 \%$ & $40 \%$ & $65 \%$ & $65 \%$ & $65 \%$ & $65 \%$ \\
\hline
\end{tabular}

Table 4

Bioassay 2: percentage of semi-engorged Amblyomma cajennense s.s. female ticks exposed to different concentrations of Acmella oleracea ethanolic extract.

\begin{tabular}{|c|c|c|c|c|c|c|c|}
\hline \multirow[t]{2}{*}{ Concentration of extract $(\mathrm{mg} / \mathrm{mL})$} & \multicolumn{7}{|c|}{ Percentage of dead ticks/days of treatment (\%) } \\
\hline & 1 st day & 2 nd day & 3 rd day & 4 th day & 5 th day & 6 th day & 7 th day \\
\hline Control 1 (distilled $\mathrm{H}_{2} 0$ ) & 0 & 0 & 0 & 0 & 0 & 0 & 0 \\
\hline Control 2 (50\% ethanol 1\% DMSO) & 0 & 0 & 0 & 0 & 0 & 0 & 0 \\
\hline 14.3 & $15 \%$ & $30 \%$ & $40 \%$ & $40 \%$ & $40 \%$ & $40 \%$ & $40 \%$ \\
\hline 16.6 & 0 & $15 \%$ & $40 \%$ & $40 \%$ & $40 \%$ & $40 \%$ & $50 \%$ \\
\hline 20 & $5 \%$ & $25 \%$ & $30 \%$ & $50 \%$ & $55 \%$ & $55 \%$ & $55 \%$ \\
\hline 25 & 0 & $25 \%$ & $40 \%$ & $55 \%$ & $55 \%$ & $55 \%$ & $65 \%$ \\
\hline 33 & 0 & $20 \%$ & $55 \%$ & $55 \%$ & $55 \%$ & $55 \%$ & $65 \%$ \\
\hline 40 & $15 \%$ & $55 \%$ & $65 \%$ & $65 \%$ & $65 \%$ & $65 \%$ & $75 \%$ \\
\hline
\end{tabular}

locomotor activity, prostration in inverted position, stretching of all legs and paralysis. In Bioassay 1, the mortality rate (60-100\%) increased with higher concentrations of ethanolic extract of $A$. oleracea $(25,50$ and $100 \mathrm{mg} / \mathrm{mL})$. In higher concentrations, the ethanolic extract effects increased throughout the observations period, and the 6th and 7th days of treatment showed the highest mortality rates (Table 2 ). The highest concentration of ethanolic extract $(100 \mathrm{mg} / \mathrm{mL}$ ) showed a mortality of $60 \%$ on the 1 st day and $100 \%$ on the 3rd day of the experiment (Table 2 ).

In the individuals belonging to control groups 1 and 2, mortality was not statistically significant and no behavioral changes or any abnormality regarding the morphology and consistence of the integument were observed during the 7-day observation period (Fig. 4; Table 2).
The results of Bioassay 1 established the mortality interval $(12.5-50 \mathrm{mg} / \mathrm{mL})$ of $A$. cajennense s.s. semi-engorged females exposed to the ethanolic extract. Based on these data, new dilutions were performed and new concentrations of ethanolic extract were obtained and used in Bioassay 2.

Bioassay 2 results showed that $A$. cajennense s.s. semi-engorged females were sensitive to all concentrations of ethanolic extract (Fig. 5; Table 4 ) and tick mortality progressively increased (75\%) in higher concentrations of the ethanolic extract $(14.3 ; 16.6 ; 20$; 25; 33; and $40 \mathrm{mg} / \mathrm{mL}$ ) (Fig. 5; Table 4). The highest mortality rate was observed in the period between the 5 th and the 7 th day of treatment (Table 4).

In the concentrations used in the bioassay 2, the semi-engorged female ticks showed immediate reactions such the decrease in the locomotor activity, prostration in inverted position, stretching of all 


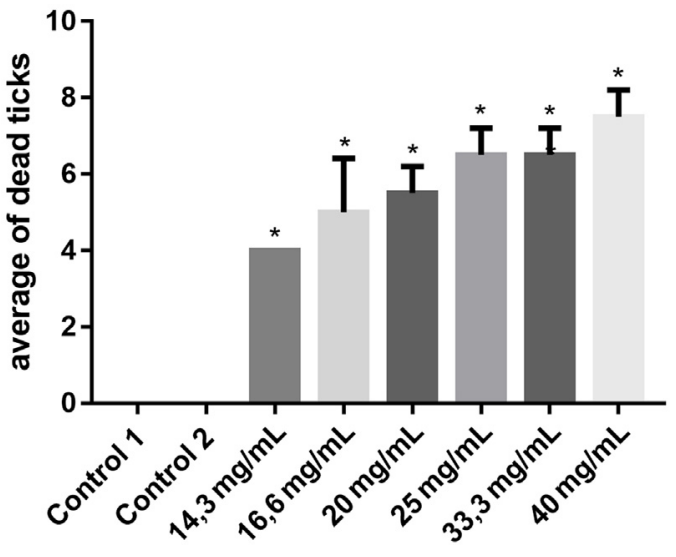

Fig. 5. Bioassay 2: average of dead of semi-engorged Amblyomma cajennense s.s. female ticks on the 7th day of exposure to different concentrations of Acmella oleracea ethanolic extract. * indicates statistically significant difference $(p<0.05) 1$. Control $1=$ distilled water; Control $2=50 \%$ ethanol and 1\% DMSO.

\section{Table 5}

Probit analysis results based on the mortality of Amblyomma. cajennense s.s. male ticks exposed to the ethanolic extract in Bioassay 2.

\begin{tabular}{ll}
\hline $\mathrm{LC}_{50}$ & $29.4534 \mathrm{mg} / \mathrm{mL}$ limits: 24.4467-41.3847 \\
Standard error & 0.0583 \\
Chi-square & 0.7747 \\
Degrees of freedom & 4 \\
P-value & 0.9418 \\
\hline
\end{tabular}

\section{Table 6}

Probit analysis results based on the mortality of semi-engorged Amblyomma. cajennense s.s. female ticks exposed to the ethanolic extract in Bioassay 2.

\begin{tabular}{ll}
\hline $\mathrm{LC}_{50}$ & $17.6335 \mathrm{mg} / \mathrm{mL}$ limits: $5.2506-23.5335$ \\
Standard error & 0.1662 \\
Chi-square & 0.1753 \\
Degrees of freedom & 4 \\
P-value & 0.9964 \\
\hline
\end{tabular}

legs and paralysis - as observed in Bioassay 1 - demonstrating that these individuals can progressively lose vitality, and eventually die.

In the individuals belonging to control group 1 and 2, mortality was not statistically significant and no behavioral changes or any abnormality regarding the morphology, coloration and consistence of the integument were observed during the 7-day observation period (Fig. 5; Table 4).

In these experimental conditions, the mortality data obtained in Bioassay 2 were submitted to Probit analysis to estimate the lethal concentration 50\% ( $\mathrm{LC}_{50}$ ) and the 95\% confidence interval, $\mathrm{g}(95)$ : $\mathrm{LC}_{50}=17.6335 \mathrm{mg} / \mathrm{mL}$ (limits: 23.5335-5.2506 mg/mL) (Table 6).

\section{Discussion}

Studies have demonstrated the potential biological effects of $A$. oleracea extracts against invertebrates (Fabry et al., 1996; Pandey et al., 2007; Ramsewak, 1999; Torres and Chávez, 2001). These effects are attributed to spilanthol, major component of these extracts and the ethanol crude extract used in the present study (Ramsewak, 1999).

This compound, obtained through ethanolic extraction, presented yield of $7.7 \pm 0.08 \%$ on a dry basis; these values were comparable to those reported in other studies using ethanol and similar methods of extraction (Dias et al., 2012; Yadav et al., 2011). Spilanthol presents good stability in ethanol extracts; therefore, ethanol was chosen as a solvent in the extract production in addition to being safe and inexpensive when compared to other solvents (Bae et al., 2010; Rodrigues et al., 2006). Furthermore, a study carried out by Resende et al. (2012) demonstrated that the ethanol presents low toxicity to ticks, not causing mortality in s $A$. cajennense adults, species used in the bioassays performed in this experiment.

In present study, analytical monitoring of spilanthol in the $A$. oleracea ethanolic extract was performed through GC/MS analysis, comparing the mass fragmentation pattern and the database library from the National Institute of Standards and Technology (NIST) Mass Spectral Search Program ${ }^{\circledR}$ (2005). The total ion chromatogram of the crude extract of $A$. oleracea also showed the presence of spilanthol, with chromatographic peak produced at 41.9 min retention time.

The bioassay Adult Immersion Test (AIT) was used to monitor the susceptibility of $A$. cajennense s.s. ticks to ethanolic extract of $A$. oleracea, once the AIT is an efficient tool to measure the sensitivity of the ticks to acaricide chemical compounds (Drummond et al., 1973; Scott, 1995).

The results obtained in the bioassays 1 and 2 showed that $A$. cajennense s.s. males were sensitive to all the A. oleracea ethanolic extract concentrations tested here $(6.2 ; 12.5 ; 14.3 ; 16.6 ; 20 ; 25 ; 33$; 40,50 and $100 \mathrm{mg} / \mathrm{mL}$ ). There was a gradual increase in mortality (5-100\%), proportional to the increase of the concentrations and to the time of exposure. At the highest concentration $(100 \mathrm{mg} / \mathrm{mL})$, the mortality rate was $100 \%$, observed after $24 \mathrm{~h}$ of exposure. Similar results were found by Roma et al. (2009) and Oliveira et al. (2011) studying Rhipicephalus sanguineus s.l. females exposed to permethrin and fipronil, which, applied at specific concentrations, were able to cause the death of $100 \%$ individuals in $24 \mathrm{~h}$.

However, semi-engorged females were not sensitive to all the ethanolic extract concentrations used here. In the lowest concentration $(6.2 \mathrm{mg} / \mathrm{mL})$, dead ticks were not found during the 7-day observation period. In the concentration of $12.5 \mathrm{mg} / \mathrm{mL}$, dead ticks were observed from the 2nd to 7th day. After the treatment with the concentrations 25,50 and $100 \mathrm{mg} / \mathrm{mL}$, dead ticks were found in the period between the $1 \mathrm{st}$ and the 7th day. In the highest concentration ( $100 \mathrm{mg} / \mathrm{mL}$ ), $100 \%$ mortality was observed after $72 \mathrm{~h}$ of exposure. These data corroborate Castro et al. (2014), who observed an increase in mortality rates of $20.7 ; 26.6$ and $59.2 \%$ for $R$. microplus exposed to hexane extract of $A$. oleracea in concentrations of 25 , 50 and $100 \mathrm{mg} / \mathrm{mL}$, respectively, confirming the dose-dependent action of the extracts of $A$. oleracea. Studies carried out by Roma et al. (2009) showed no mortality for ticks exposed to lower concentrations of chemical permethrin; however, the application of higher concentrations caused a progressive mortality rate increase. Farias et al. (2009, 2007), studying the species Boophilus microplus, Anocentor nitens and $R$. sanguineus s.l. exposed to andiroba seed oil, detected $100 \%$ mortality in the females exposed to the higher concentrations tested $(25,30,50$ and $100 \%)$, except in $10 \%$, whose mortality was $90 \%$ on the second day after the exposure, with the oviposition of infertile eggs.

Moreover, all the individuals tested and exposed to different concentrations of the extract displayed behavioral alterations were also observed, such as the decrease of locomotor activity, prostration in inverted position, stretching of the legs and paralysis. The occurrence of such alterations were also observed by Roma et al. (2009) and Oliveira et al. (2011) in R. sanguineus s.l. ticks exposed to fipronil and permethrin, respectively.

In the present study, we verified that the ethanolic extract of $A$. oleracea, even at low concentrations, showed a remarkable level of toxicity to ticks, similar to that of other natural products or extracts, such as azadirachtin, thymol, carvacrol, Ageratum conyzoides and Artemisia absinthium (Koc et al., 2013; Matos et al., 2014b; Parveen et al., 2014; Srivastava et al., 2008). In addition, this study confirms the acaricidal efficacy of $A$. oleracea extract, corroborating Castro et al. (2014), who showed mortality rates of $100 \%$ in larvae exposed to $6.2 \mathrm{mg} / \mathrm{mL}$ and $98.2 \%$ in engorged $R$. microplus females 
exposed to the concentration of $150 \mathrm{mg} / \mathrm{mL}$ of the extract. The same authors verified that the hexane extract from $A$. oleracea was able to reduce oviposition and the viability of eggs, relevant information to ground further studies aiming to develop strategies to control these ectoparasites.

The literature also reports that the extract obtained from A. oleracea is able to control the proliferation of other arthropods, functioning efficiently against Aedes aegypti (Diptera) larvae, Plutella xylostella (Lepidoptera) adults and American cockroaches (Periplaneta americana) (Blattodea) (Kadir et al., 1989; Ramsewak, 1999; Sharma et al., 2012).

Therefore, the present study established that the $A$. oleracea ethanolic extract presents a $\mathrm{LC}_{50}$ of $29.5 \mathrm{mg} / \mathrm{mL}$ for A. cajennense s.s. males and $17.6 \mathrm{mg} / \mathrm{mL}$ for semi-engorged females, confirming the high efficiency of this extract in comparison with others obtained from Asteraceae plants, such as Calea serrata and Artemisia annua (Chagas et al., 2011; Ribeiro et al., 2008). The $\mathrm{LC}_{50}$ obtained for the semi-engorged females $(17.6335 \mathrm{mg} / \mathrm{mL})$ differs from that determined by Castro et al. (2014) for $R$. microplus engorged females $(79.7 \mathrm{mg} / \mathrm{mL})$ exposed to A. oleracea hexane extract. This difference can be explained by the higher level and preservation of the active principle spilanthol, a possible variation caused by the use of different solvents and extraction processes. In addition, climatic conditions, growing site, harvesting season, soil, fertilizing, rainfall, and development or flowering stages are important factors to be considered when evaluating the concentration of spilanthol in A. oleracea plants (Cavalcanti, 2008).

Natural chemical acaricides present several advantages when compared to synthetic ones. Most importantly, natural chemicals minimize the development of resistant individuals, once plant extracts comprise a pool of active ingredients and can be used to a lesser extent. In addition, these acaricides are affordable and less harmful to the environment and nontarget organisms. Thus, this study analyzed the potential of the ethanol extract obtained from A. oleracea flowers, leaves and stems to control A. cajennense s.s fed males and semi-engorged females, bringing relevant data on the use of this chemical as a sustainable tool to control these ectoparasites.

\section{Conflict of interest}

The author(s) declare(s) that there is no conflict of interest regarding the publication of this paper.

\section{Acknowledgments}

We would like to thank to São Paulo Research Foundation (FAPESP) Grant no. 2015/01496-5 and CAPES/Brazil for financial support.

\section{References}

Abbas, R.Z., Zaman, M.A., Colwell, D.D., Gilleard, J., Iqbal, Z., 2014. Acaricide resistance in cattle ticks and approaches to its management: the state of play. Vet. Parasitol. 203, 6-20, http://dx.doi.org/10.1016/j.vetpar.2014.03.006.

Bae, S.S., Ehrmann, B.M., Ettefagh, K.A., Cech, N.B., 2010. A validated liquid chromatography-electrospray ionization-mass spectrometry method for quantification of spilanthol in Spilanthes acmella (L.) Murr. Phytochem. Anal. 21, 438-443, http://dx.doi.org/10.1002/pca.1215.

Beati, L., Nava, S., Burkman, E.J., Barros-Battesti, D.M., Labruna, M.B., Guglielmone, A., Cáceres, a, Guzmán-Cornejo, A.G., León, C.M., Durden, R., a, L., Faccini, J.L.H., 2013. Amblyomma cajennense (Fabricius, 1787) (Acari: Ixodidae), the Cayenne tick: phylogeography and evidence for allopatric speciation. BMC Evol. Biol. 13, 267, http://dx.doi.org/10.1186/1471-2148-13-267.

Bechara, G., S, M.P.J., Ferreira, B., Garcia, M., 1995. Rhipicephalussanguineus tick in Brazil: feeding and reproductive aspects under laboratorial conditions. Braz. J. Vet. Parasitol. 4, 61-66.

Borges, L.M., Sousa, L.A., Barbosa Cda, S., 2011. Perspectives for the use of plant extracts to control the cattle tick Rhipicephalus (Boophilus) microplus. Rev. Bras. Parasitol. Vet. 20, 89-96.
Castro, K.N.C., Lima, D.F., Vasconcelos, L.C., Leite, J.R.S.A., Santos, R.C., Paz Neto, A.A. Costa-Júnior, L.M., 2014. Acaricide activity in vitro of Acmella oleracea against Rhipicephalus microplus. Parasitol. Res. 113, 3697-3701, http://dx.doi.org/10. 1007/s00436-014-4034-2.

Cavalcanti, V.M.S., 2008. Extração de espilantol de Spilanthes acmella var oleracea com dióxido de carbono supercrítico. Tese (Doutorado em Eng. Process). Universidade Estadual de Campinas, Campinas - SP.

Chagas, A.C., Georgetti, C.S., Carvalho, C.O., Oliveira, M.C., Rodrigues, R.A., Foglio, M.A., Magalhães, P.M., 2011. In vitro activity of Artemisia annua L. (Asteraceae) extracts against Rhipicephalus (Boophilus) microplus. Rev. Bras. Parasitol. Vet. 20, 31-35, http://dx.doi.org/10.1590/S1984-29612011000100007.

Crampton, A., Baxter, G., Barker, S., 1999. Identification and characterisation of a cytochrome P450 gene and processed pseudogene from an arachnid: the cattle tick Boophilus microplus. Insect Biochem. Mol. Biol. 29, 377-384, http://dx.doi. org/10.1016/S0965-1748(99)00013-2.

Dias, A.M.A., Santos, P., Seabra, I.J., Júnior, R.N.C., Braga, M.E.M., de Sousa, H.C., 2012. Spilanthol from Spilanthes acmella flowers, leaves and stems obtained by selective supercritical carbon dioxide extraction. J. Supercrit. Fluids 61, 62-70, http://dx.doi.org/10.1016/j.supflu.2011.09.020.

Dietrich, G., Dolan, M.C., Peralta-Cruz, J., Schmidt, J., Piesman, J., Eisen, R.J., Karchesy, J.J., 2006. Repellent activity of fractioned compounds from Chamaecyparis nootkatensis essential oil against nymphal Ixodes scapularis (Acari: Ixodidae). J. Med. Entomol. 43, 957-961, http://dx.doi.org/10.1093/ jmedent/43.5.957.

Drummond, R.O., Ernst, S.E., Trevino, J.L., Gladney, W.J., Graham, O.H., 1973. Boophilus annulatus and B. microplus: laboratory tests of insecticides. J. Econ. Entomol. 66, 130-133.

Dubey, S., Maity, S., Singh, M., Saraf, S.A., Saha, S., 2013. Phytochemistry, pharmacology and toxicology of Spilanthes acmella: a review. Adv. Pharmacol. Sci. 2013, 423750, http://dx.doi.org/10.1155/2013/423750.

Estrada-Peña, A., Tarragona, E.L., Vesco, U., Meneghi, D., De Mastropaolo, M., Mangold, A.J., Guglielmone, A.A., Nava, S., 2014. Divergent environmental preferences and areas of sympatry of tick species in the Amblyomma cajennense complex (Ixodidae). Int. J. Parasitol. 44, 1081-1089, http://dx.doi. org/10.1016/j.ijpara.2014.08.007.

Fabry, W., Okemo, P., Ansorg, R., 1996. Fungistatic and fungicidal activity of east African medicinal plants. Mycoses 39, 67-70

Farias, M.P.O., Sousa, D.P., Arruda, A.C., Arruda, M.S.P., Wanderley, A.G., Alves, L.C., Faustino, M.A.G., 2007. Eficácia in vitro do óleo da Carapa guianensis Aubl. (andiroba) no controle de Boophilus microplus (Acari Ixodidae). Rev. Bras. Plantas Med. 9, 68-71.

Farias, M.P.O., Sousa, D.P., Arruda, A.C., Wanderley, A.G., Teixeira, W.C., Alves, L.C. Faustino, M.A.G., 2009. Potencial acaricida do óleo de andiroba Carapa guianensis Aubl. sobre fêmeas adultas ingurgitadas de Anocentor nitens Neumann, 1897 e Rhipicephalus sanguineus Latreille, 1806. Arq. Bras. Med. Vet. e Zootec. 61, 877-882, http://dx.doi.org/10.1590/S0102-09352009000400015.

Favoreto, R., Gilbert, B., 2010. Estado da Arte/State of the Art - Acmella oleracea (L.) R.K. Jansen (Asteraceae) - Jambu. Rev. Fitos 5, 83-91

Kadir, H.A., Zakaria, M.B., Kechil, A.A., Azirun, M.D.S., 1989. Toxicity and electrophysiological effects of Spilanthes amella Murr. extracts on Periplaneta americana L. Pestic. Sci. 25, 329-335, http://dx.doi.org/10.1002/ps.2780250402.

Koc, S., Oz, E., Cinbilgel, I., Aydin, L., Cetin, H., 2013. Acaricidal activity of Origanum bilgeri P.H Davis (Lamiaceae) essential oil and its major component, carvacrol against adults Rhipicephalus turanicus (Acari: Ixodidae). Vet. Parasitol. 193, 316-319, http://dx.doi.org/10.1016/j.vetpar.2012.11.010.

Matos, R., da, S., Daemon, E., Camargo-Mathias, M.I., Furquim, K.C.S., Sampieri, B.R., Remédio, R.N., Araújo, L.X., Novato, T.P.L., 2014a. Histopathological study of ovaries of Rhipicephalus sanguineus (Acari: Ixodidae) exposed to different thymol concentrations. Parasitol. Res. 113, 4555-4565, http://dx.doi.org/10. 1007/s00436-014-4145-9.

Matos, R., da, S., Melo, D.R., Monteiro, C.M.O., Zeringóta, V., Senra, T.O.S., Calmon, F. Maturano, R., Prata, M.C.A., Daemon, E., 2014b. Determination of the susceptibility of unengorged larvae and engorged females of Rhipicephalus microplus (Acari: Ixodidae) to different methods of dissolving thymol. Parasitol. Res. 113, 669-673, http://dx.doi.org/10.1007/s00436-013-3694-7.

Nigrinis, L.S.O., de Caro, J.O., Olarte, E.N., 1986. Estudio fitofarmacológico de la fraccion liposoluble de las flores de la Spilanthes americana (Mutis) parte I: Estudio fitoquimico. Rev. Colomb. Ciências Químico-Farmacêuticas 15, 37-47.

Nolan, J., 1985. Mechanisms of resistance to chemicals in arthropod parasites of veterinary importance. Vet. Parasitol. 18, 155-166, http://dx.doi.org/10.1016/ 0304-4017(85)90064-0.

Oliveira, P.R., Bechara, G.H., Camargo-Mathias, M.I., 2008. Evaluation of cytotoxic effects of fipronil on ovaries of semi-engorged Rhipicephalus sanguineus (Latreille, 1806) (Acari: Ixodidae) tick female. Food Chem. Toxicol. 46, 2459-2465, http://dx.doi.org/10.1016/j.fct.2008.03.034.

Oliveira, P.R., Bechara, G.H., Morales, M.A.M., Mathias, M.I.C., 2009. Action of the chemical agent fipronil on the reproductive process of semi-engorged females of the tick Rhipicephalus sanguineus (Latreille, 1806) (Acari: Ixodidae) Ultrastructural evaluation of ovary cells. Food Chem. Toxicol. 47, 1255-1264, http://dx.doi.org/10.1016/j.fct.2009.02.019.

Oliveira, P.R. Bechara, G.H., Denardi, S.E., Pizano, M.A., Mathias, M.I.C., 2011. Toxicity effect of the acaricide fipronil in semi-engorged females of the tick Rhipicephalus sanguineus (Latreille, 1806) (Acari: Ixodidae): preliminary determination of the minimum lethal concentration and LC(50). Exp. Parasitol. 127, 418-422, http://dx.doi.org/10.1016/j.exppara.2010.09.009. 
Pandey, V., Agrawal, V., Raghavendra, K., Dash, A.P., 2007. Strong larvicidal activity of three species of Spilanthes (Akarkara) against malaria (Anopheles stephensi Liston Anopheles culicifacies, species C) and filaria vector (Culex quinquefasciatus Say). Parasitol. Res. 102, 171-174, http://dx.doi.org/10.1007/ s00436-007-0763-9.

Panella, N.A., Dolan, M.C., Karchesy, J.J., Xiong, Y., Peralta-cruz, J., Khasawneh, M., Montenieri, J.A., Maupin, G.O., 2005. Use of novel compounds for pest control: insecticidal and acaricidal activity of essential oil components from heartwood of alaska yellow cedar. J. Med. Entomol. 42, 352-358, http://dx.doi.org/10. 1093/jmedent/42.3.352.

Parveen, S., Godara, R., Katoch, R., Yadav, A., Verma, P.K., Katoch, M., Singh, N.K. 2014. In vitro evaluation of ethanolic extracts of Ageratum conyzoides and Artemisia absinthium against cattle tick, Rhipicephalus microplus. Sci. World J. 2014, 1-6, http://dx.doi.org/10.1155/2014/858973.

Pruett, J.H., 1999. Immunological control of arthropod ectoparasites - a review. Int. J. Parasitol. 29, 25-32, http://dx.doi.org/10.1016/S0020-7519(98)00172-6.

Ramsewak, R., 1999. Bioactive N-isobutylamides from the flower buds of Spilanthes acmella. Phytochemistry 51, 729-732, http://dx.doi.org/10.1016/S00319422(99)00101-6.

Remedio, R.N., Nunes, P.H., Anholeto, L.A., Oliveira, P.R., Camargo-Mathias, M.I., 2015. Morphological effects of neem (Azadirachta indica A. Juss) seed oil with known azadirachtin concentrations on the oocytes of semi-engorged Rhipicephalus sanguineus ticks (Acari: Ixodidae). Parasitol. Res. 114, 431-444, http://dx.doi.org/10.1007/s00436-014-4200-6.

Resende, J.D., de, S.A., Daemon, E., Monteiro, C.M., de, O., Maturano, R., Prata, M.C. de, A., Ferreira Rodrigues, A.F.S., 2012. Toxicity of solvents and surfactants to Amblyomma cajennense (Fabricius, 1787) (Acari: Ixodidae) and Dermacentor nitens (Neumann, 1897) (Acari: Ixodidae) larvae. Exp. Parasitol. 131, 139-142, http://dx.doi.org/10.1016/j.exppara.2012.03.002.

Ribeiro, V.L.S., Avancini, C., Gonçalves, K., Toigo, E., von Poser, G., 2008. Acaricidal activity of Calea serrata (Asteraceae) on Boophilus microplus and Rhipicephalus sanguineus. Vet. Parasitol. 151, 351-354, http://dx.doi.org/10.1016/j.vetpar. 2007.11.007.

Rodrigues, R.A.F., Foglio, M.A., Boaventura Júnior, S., Santos, A., da, S., Rehder, V.L.G., 2006. Otimização do processo de extração e isolamento do antimalárico artemisinina a partir de Artemisia annua L. Quim. Nova 29, 368-372, http://dx. doi.org/10.1590/S0100-40422006000200030.
Roma, G.C., de Oliveira, P.R., Pizano, M.A., Camargo Mathias, M.I., 2009 Determination of LC(50) of permethrin acaricide in semi-engorged females of the tick Rhipicephalus sanguineus (Latreille, 1806) (Acari: Ixodidae). Exp. Parasitol. 123, 269-272, http://dx.doi.org/10.1016/j.exppara.2009.08.001.

Scoles, G.A., Ueti, M.W., 2013. Amblyomma cajennense is an intrastadial biological vector of Theileria equi. Parasites Vectors 6, 306, http://dx.doi.org/10.1186/ 1756-3305-6-306.

Scoles, G.A., Hutcheson, H.J., Schlater, J.L., Hennager, S.G., Pelzel, A.M., Knowles, D.P., 2011. Equine piroplasmosis associated with Amblyomma cajennense Ticks, Texas, USA. Emerg. Infect. Dis. 17, 1903-1905, http://dx.doi.org/10.3201/ eid1710.101182.

Scott, J.A., 1995. The molecular genetics of resistance: resistance as a response to stress. Florida Entomol. 78, 399-414, http://dx.doi.org/10.2307/3495526.

Sharma, A., Kumar, V., Rattan, R.S., Kumar, N., Singh, B., 2012. Insecticidal toxicity of spilanthol from Spilanthes acmella Murr. against Plutella xylostella L. Am. J. Plant Sci. 03, 1568-1572, http://dx.doi.org/10.4236/ajps.2012.311189.

Soares, H.S., Barbieri, A.R.M., Martins, T.F., Minervino, A.H.H., de Lima, J.T.R., Marcili, A., Gennari, S.M., Labruna, M.B., 2015. Ticks and rickettsial infection in the wildlife of two regions of the Brazilian Amazon. Exp. Appl. Acarol. 65 125-140, http://dx.doi.org/10.1007/s10493-014-9851-6.

Srivastava, R., Ghosh, S., Mandal, D.B., Azhahianambi, P., Singhal, P.S., Pandey, N.N. Swarup, D., 2008. Efficacy of Azadirachta indica extracts against Boophilus microplus. Parasitol. Res. 104, 149-153, http://dx.doi.org/10.1007/s00436-0081173-3.

Torres, J.M., Chávez, A.G., 2001. Alcamidas en plantas: distribución e importancia. Av. y Perspect. 20, 377-387.

Vendramini, M.C.R., Camargo-Mathias, M.I., Faria, A.U., Bechara, G.H., Oliveira, P.R., Roma, G.C., 2012. Cytotoxic effects of andiroba oil (Carapa guianensis) in reproductive system of Rhipicephalus sanguineus (Latreille, 1806) (Acari: Ixodidae) semi-engorged females. Parasitol. Res. 111, 1885-1894, http://dx. doi.org/10.1007/s00436-012-3031-6.

Yadav, R., Yadav, N., Kharya, M.D., Savadi, R., 2011. Preliminary studies on diuretic effect of Spilanthes acmella leaves extracts in rats. Int. J. Pharm. Pharm. Sci. 3. $245-247$. 